\title{
Relation between body mass index and mortality in an unusually slim cohort
}

\author{
M Thorogood, P N Appleby, T J Key, J Mann
}

J Epidemiol Community Health 2003;57:130-133

\begin{abstract}
Study objective: To investigate the relation between body mass index and mortality in an unusually slim cohort.

Design: Prospective cohort study.

Setting: United Kingdom.

Participants: About 11000 non-meat eaters and their meat eating friends and relatives, with a median age of 33 years were recruited between 1980 and 1984 . More than $20 \%$ of the cohort had a self reported BMI below $20 \mathrm{~kg} / \mathrm{m}^{2}$ at recruitment. There were 195000 person years of observation after a mean of 18.0 years of follow up.

Main results: The characteristics of participants with a BMI below $18 \mathrm{~kg} / \mathrm{m}^{2}$ were favourable to a lower risk of cardiovascular disease. Nevertheless, these participants had an increased all cause death rate ratio $(2.07,95 \% \mathrm{Cl} 1.58$ to 2.70$)$ in comparison with participants who had a $\mathrm{BMI}$ between 20 and $22 \mathrm{~kg} / \mathrm{m}^{2}$. The death rate ratio for the slimmest category was also significantly increased for circulatory diseases (including ischaemic heart disease and cerebrovascular disease), respiratory diseases, and all other causes combined excluding all malignant neoplasms. This finding was consistent across a range of subgroups.

Conclusions: Lean men and women $\left(B M l<18 \mathrm{~kg} / \mathrm{m}^{2}\right)$ experience increased all cause mortality compared with those with a BMI between 20 and $22 \mathrm{~kg} / \mathrm{m}^{2}$. This pattern is not seen for cancer mortality, but is found for cardiovascular and respiratory diseases. It is important that public health messages regarding healthy eating are aimed at maintaining a healthy body weight rather than just "losing weight".
\end{abstract}

See end of article for authors' affiliations

Correspondence to: Dr M Thorogood, London School of Hygiene and Tropical Medicine, Keppel Street, London WCIE 7HT, Ishtm.ac.uk

Accepted for publication 14 June 2002
T he current epidemic of obesity and its consequent health burden has been well documented. ${ }^{1-3}$ However, in cohort studies mortality has often shown a $\mathrm{J}$ shaped relation with body mass index (BMI), with a small upturn in those with a low BMI (commonly below 20 or $22 \mathrm{~kg} / \mathrm{m}^{2}$ ), as well as a greater increase in those with a BMI above $30 \mathrm{~kg} / \mathrm{m}^{2}$. The increased mortality in underweight people has been observed to be more prominent when considering deaths in old age and among men, and cannot be explained by confounding by smoking history or by pre-existing disease, whereas overweight and obesity confer a larger increase in mortality in middle age. ${ }^{4-6}$

Almost all the data on variations in mortality with BMI have come from populations with a small tail of people of low BMI, and considerably more people of high BMI. In this paper we report a long term follow up study of an unusual group of some 11000 people, including non-meat eaters and their meat eating friends and relatives, in which more than $20 \%$ of the cohort had a self reported BMI below $20 \mathrm{~kg} / \mathrm{m}^{2}$ at recruitment.

\section{SUBJECTS AND METHODS}

Recruitment to the Oxford Vegetarian Study has been described previously. ${ }^{7}$ Briefly, the cohort was recruited between 1980 and 1984 through the Vegetarian Society of the UK and the news media, with non-vegetarians recruited by the vegetarian participants from among their friends and relatives. Subjects completed a questionnaire that included questions about their usual diet, occupation, smoking habits, and physical activity. Participants were also asked to report their height and weight and to give details of any current or past illnesses. Between 1984 and 1986 all surviving participants aged less than 70 years were asked to provide a blood sample. There was a response rate of about $40 \%$, and serum cholesterol concentrations were measured in just over 3700 blood samples. Follow up was by record linkage with the National Health Service Central Register. Subjects were included in the analysis if they were aged 16-89 at entry, had not been diagnosed with a malignant cancer before recruitment (except for non-melanoma skin cancer, ICD9 code 173), and could be classified according to their BMI and smoking habits. Subjects in the study were also classified according to whether or not they had pre-existing cardiovascular disease or diabetes at recruitment, this being defined as previous or current diabetes, hypertension, angina, heart disease, or stroke. Social class was determined according to the occupation of the subject, or that of their spouse in the case of housewives. Subjects were followed up to the end of 2000, subject to censoring at age 90 . They were divided into seven BMI categories $(<18$, $18<20,20<22,22<24,24<26,26<28,28+\mathrm{kg} / \mathrm{m}^{2}$ ) according to their self reported BMI at recruitment. All deaths were coded for underlying cause of death using the 9th revision of the International Classification of Diseases (ICD9).

Death rate ratios by BMI category relative to the reference category $\left(20<22 \mathrm{~kg} / \mathrm{m}^{2}\right)$ were calculated by Cox regression using the STATA statistical package ${ }^{8}$ for each of the following causes of death: all causes (ICD9 001-999); all malignant neoplasms (140-208); diseases of the circulatory system (390459), including ischaemic heart disease (410-414), and cerebrovascular disease (430-438); diseases of the respiratory system (460-519); all other causes of death (001-139, 210-389, 520-999). All death rate ratios were adjusted for age at recruitment (in 11 categories: <40, 40-44, 45-49, 50-54, 55-59, 60-64, 65-69, 70-74, 75-79, 80-84, 85-89), sex, smoking habits (in four categories: never smokers, former smokers, light smokers, and heavy smokers) and reported pre-existing cardiovascular disease or diabetes as described above. Heavy smokers were subjects smoking 15 or more cigarettes per day, 
Table 1 Baseline characteristics of the subjects by BMI category

\begin{tabular}{|c|c|c|c|c|c|c|c|}
\hline \multirow[b]{2}{*}{ Characteristic } & \multicolumn{7}{|c|}{ BMI $\left(\mathrm{kg} / \mathrm{m}^{2}\right)$} \\
\hline & $<18$ & $18-20$ & $20-22$ & $22-24$ & $24-26$ & $26-28$ & $\geqslant 28$ \\
\hline Number ( $\%$ of total) & $372(3.4)$ & $2013(18.5)$ & $3482(32.1)$ & $2774(25.5)$ & $1350(12.4)$ & $530(4.9)$ & $337(3.1)$ \\
\hline Female & 78.0 & 74.5 & 66.1 & 54.6 & 50.1 & 48.5 & 57.9 \\
\hline Median age at recruitment & 32 & 30 & 31 & 34 & 41 & 47 & 47 \\
\hline \multicolumn{8}{|l|}{ Smoking } \\
\hline never smoker & 61.3 & 57.2 & 56.7 & 52.3 & 47.7 & 44.5 & 44.2 \\
\hline former smoker & 19.9 & 22.6 & 23.8 & 28.6 & 33.9 & 34.7 & 35.3 \\
\hline light smoker* & 11.6 & 13.4 & 11.9 & 11.6 & 10.8 & 11.1 & 13.1 \\
\hline heavy smoker* & 7.3 & 6.8 & 7.7 & 7.6 & 7.6 & 9.6 & 7.4 \\
\hline \multicolumn{8}{|l|}{ Social class } \\
\hline |-II & 38.4 & 46.0 & 49.6 & 49.9 & 49.0 & 44.7 & 44.5 \\
\hline III-V & 23.1 & 27.9 & 29.4 & 28.6 & 28.3 & 29.1 & 30.6 \\
\hline unclassified & 38.4 & 26.1 & 21.0 & 21.6 & 22.7 & 26.2 & 24.9 \\
\hline Pre-existing cardiovascular disease or diabetes $\dagger$ & 6.7 & 5.9 & 5.4 & 7.6 & 10.7 & 14.7 & 19.0 \\
\hline Vegetarian $\ddagger$ & 63.4 & 53.8 & 43.6 & 39.3 & 31.7 & 26.6 & 27.0 \\
\hline for more than 5 years & 40.1 & 36.5 & 27.9 & 26.7 & 23.9 & 19.6 & 18.7 \\
\hline member of vegetarian groups & 37.4 & 27.5 & 21.9 & 21.5 & 18.3 & 15.5 & 14.8 \\
\hline vegan $\ddagger$ & 4.6 & 4.5 & 3.3 & 3.1 & 1.7 & 1.7 & 0.9 \\
\hline \multicolumn{8}{|l|}{ Estimated animal fat intake§ } \\
\hline bottom third & 40.3 & 37.0 & 34.8 & 33.7 & 26.5 & 23.9 & 25.5 \\
\hline middle third & 32.2 & 32.7 & 32.6 & 32.5 & 35.2 & 38.6 & 39.8 \\
\hline top third & 27.5 & 30.3 & 32.6 & 33.9 & 38.3 & 37.5 & 34.7 \\
\hline \multicolumn{8}{|l|}{ Estimated dietary fibre intake§ } \\
\hline bottom third & 24.5 & 27.1 & 32.0 & 34.6 & 40.0 & 42.9 & 48.7 \\
\hline middle third & 33.3 & 33.2 & 32.3 & 34.2 & 34.9 & 32.7 & 35.4 \\
\hline top third & 42.1 & 39.7 & 35.7 & 31.2 & 25.1 & 25.4 & 15.9 \\
\hline \multicolumn{8}{|l|}{ Estimated alcohol intake } \\
\hline$<1$ unit per week & 44.1 & 33.0 & 27.1 & 26.1 & 26.6 & 25.0 & 34.4 \\
\hline 1-7 units per week & 35.1 & 41.3 & 40.3 & 38.5 & 36.3 & 33.4 & 40.7 \\
\hline$>7$ units per week & 20.7 & 25.6 & 32.6 & 35.3 & 37.1 & 41.6 & 24.9 \\
\hline "High" level of exerciseף & 26.2 & 31.0 & 33.2 & 33.3 & 27.4 & 22.5 & 17.4 \\
\hline Family history of disease** & 26.8 & 27.4 & 29.5 & 29.9 & 29.0 & 30.2 & 33.0 \\
\hline Cholesterol measurements available & 28.8 & 34.4 & 35.8 & 34.0 & 35.0 & 29.6 & 33.8 \\
\hline Mean total cholesterol $(\mathrm{mmol} / \mathrm{l}) \dagger \dagger$ & 5.40 & 5.40 & 5.55 & 5.72 & 5.78 & 5.92 & 6.07 \\
\hline Mean LDL-cholesterol (mmol/l) †† & 3.23 & 3.22 & 3.35 & 3.50 & 3.55 & 3.65 & 3.82 \\
\hline Mean HDL-cholesterol (mmol/l)†† & 1.71 & 1.67 & 1.65 & 1.63 & 1.57 & 1.51 & 1.48 \\
\hline Mean LDL- to HDL-C ratio†† & 2.03 & 2.06 & 2.14 & 2.26 & 2.38 & 2.60 & 2.91 \\
\hline \multicolumn{8}{|c|}{ 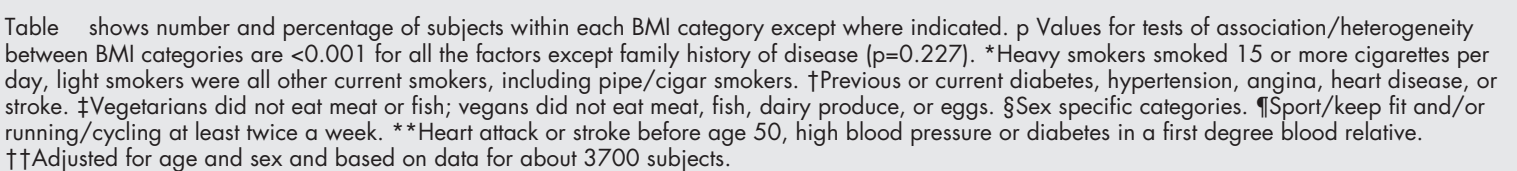 } \\
\hline
\end{tabular}

and light smokers were all other current smokers, including those smoking less than this amount or an unknown number of cigarettes per day, and other tobacco users.

\section{RESULTS}

There were 10858 subjects in the analysis, with a median age of 33 years at recruitment and mean follow up of 18.0 years, giving more than 195000 person years of observation. In the lower BMI categories there were comparatively more women, and the median age at recruitment was significantly lower $(\mathrm{p}<0.001$; table 1$)$. Conversely, there was a significantly higher proportion of subjects with pre-existing cardiovascular disease or diabetes in the heavier BMI categories, and a significantly lower proportion of vegetarian subjects (both $\mathrm{p}<0.001$ ). There was a higher intake of dietary fibre and a lower intake of animal fat in the leanest category. Blood lipid measurements were available for just over 3700 subjects. Age and sex adjusted mean values of total cholesterol, LDL-cholesterol, HDLcholesterol and the LDL-cholesterol to HDL-cholesterol ratio each showed a clear gradient from low to high BMI, with the leanest category having the most favourable lipid profile (table 1).

There were 1134 deaths before age 90 years. Table 2 shows the death rate ratios by BMI category for all causes of death combined and for selected causes of death. By comparison with participants with a BMI between 20 and $22 \mathrm{~kg} / \mathrm{m}^{2}$, those with a BMI below $18 \mathrm{~kg} / \mathrm{m}^{2}$ had a significantly increased death rate ratio for all causes of death combined of 2.07 (95\% CI 1.58 to 2.70) after adjustment for age at recruitment, gender, smoking, and pre-existing cardiovascular disease or diabetes, and for each of the selected causes of death except for all malignant neoplasms. The death rate ratio for all causes of death in the most overweight category $\left(28 \mathrm{~kg} / \mathrm{m}^{2}\right.$ or more) was also increased, but not by as much and the increase was not quite significant ( 1.28 (0.97 to 1.70$))$, although the death rate ratios for circulatory diseases and ischaemic heart disease in this category both showed significant increase. A similar pattern was evident when data for men and women were analysed separately, and when vegetarians and nonvegetarians were analysed separately (results not shown).

Low BMI may be a consequence of chronic illness. To explore this possibility we repeated the analysis excluding the first five years of follow up. The same pattern of mortality was evident (results not shown). Cigarette smoking is associated with a lower BMI, so we repeated the analysis including only people who reported never having smoked. Once again the same pattern was evident (results not shown). Finally, we examined the hypothesis that the high mortality in the lowest BMI category might be unduly influenced by elderly participants. We therefore repeated the analysis including only the 9195 subjects aged less than 60 at entry to the study. There were 347 deaths before 90 in this group, and, once again, the same pattern of mortality was evident (results not shown).

Because diet is an important risk factor for circulatory disease we also adjusted the relation between BMI and mortality 


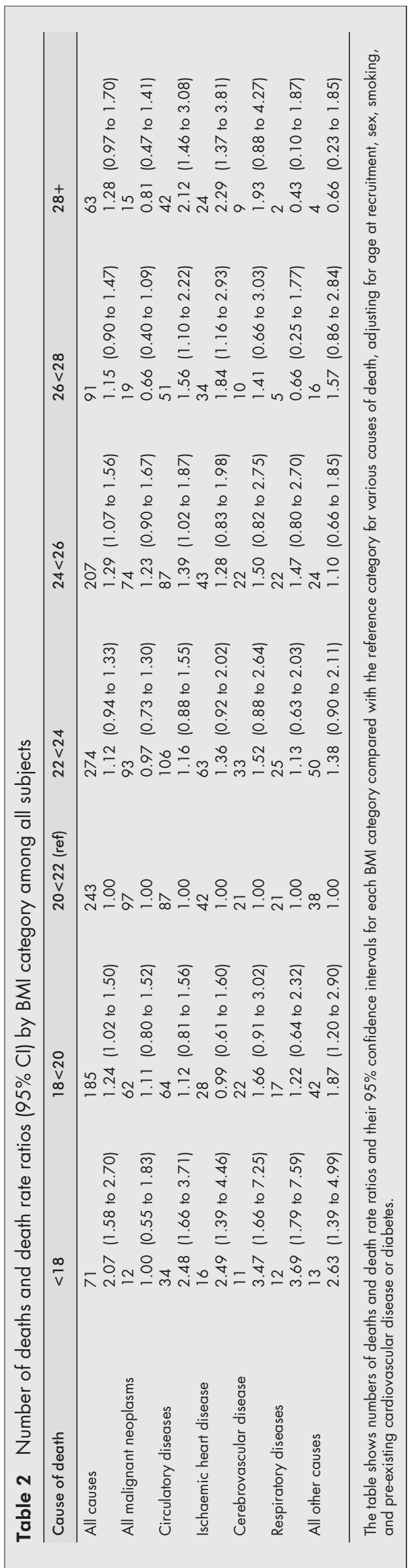

from circulatory diseases, IHD, and cerebrovascular disease for intakes of animal fat and dietary fibre. The adjustments made virtually no difference to the relations observed (results not shown).

\section{DISCUSSION}

A previous analysis of this cohort has shown a $\mathrm{J}$ shaped relation between BMI and mortality for both ischaemic heart disease and all causes of death. ${ }^{9}$ The same paper also reported that increasing intakes of total and saturated animal fat were associated with increased ischaemic heart disease mortality. In this paper we use further years of follow up and greater numbers of deaths to explore the relation between BMI and mortality further, with a finer distinction of BMI categories, more causes of death and more information about other variables.

Over $20 \%$ of the cohort had a BMI below $20 \mathrm{~kg} / \mathrm{m}^{2}$ (table 1 ). This is in contrast with the BMI found in a random sample of British men and women aged 16 to 64 years measured in $1984,{ }^{10}$ the year that recruitment to our study ended. Just $10 \%$ of British men and 14\% of British women had a BMI below 20 $\mathrm{kg} / \mathrm{m}^{2}$, while $6 \%$ of British men and $8 \%$ of British women had a BMI greater than $30 \mathrm{~kg} / \mathrm{m}^{2}$ compared with $1.2 \%$ of men and $1.5 \%$ of women of the same age in our study (table 3 ). As we have very few obese people in this cohort we are unable to examine the mortality risk associated with obesity. However, there was an increase in circulatory diseases mortality among heavier subjects, with significantly increased death rate ratios in the three categories with a BMI greater than $24 \mathrm{~kg} / \mathrm{m}^{2}$. The data for all malignant neoplasms indicate no association of risk with BMI within the range of values included. The cohort enjoys remarkably low mortality overall, with an SMR of 52 (95\% CI 49 to 56) in comparison with the population of England and Wales. ${ }^{1 .}$

The characteristics of the lowest BMI category are almost all favourable to a lower risk of cardiovascular disease. This category includes a higher proportion of non-smokers, of people with no pre-existing cardiovascular disease or diabetes, or no family history of heart disease or diabetes, of people in the bottom third of animal fat intake, and of people in the top third of dietary fibre intake. The serum lipid profile of the leanest category is also favourable. There is no strong trend in reported level of exercise. The only variable for which the slimmest people might be considered to be at increased risk of cardiovascular disease is in their lower alcohol intake, with $44 \%$ of participants in this category consuming less than one unit of alcohol per week. However, there is a generally low intake of alcohol in the other BMI categories as well. It is striking, therefore, that we have shown that a low BMI (below $18 \mathrm{~kg} / \mathrm{m}^{2}$ ) is associated with a significantly higher mortality from all causes of death (death rate ratio 2.07 (95\% CI 1.58 to $2.70)$ ) and from circulatory diseases (death rate ratio 2.48 ( 1.66 to 3.71$)$ ). In fact, this pattern is evident for all of the selected causes of death except all malignant neoplasms. Moreover, the data are remarkably robust in a series of analyses investigating possible confounding factors, including smoking and pre-existing cardiovascular disease or diabetes.

One possible weakness of the study is that height and weight are self reported. Both men and women tend to err towards a "preferred" body size when reporting their height and weight. ${ }^{12}$ That is, thin people tend to overestimate their BMI and fat people tend to underestimate it. Measured height and weight might therefore show rather flatter $\mathrm{J}$ shaped curves than we have reported here.

In most studies of mortality and BMI, the lowest BMI category is less than 21 or $22 \mathrm{~kg} / \mathrm{m}^{2}$. Few studies have reported on mortality in groups with very low BMI. We identified four relevant studies from high income countries. The four studies were all of large populations with a small proportion of people of low body mass index. ${ }^{13-15}$ None of the populations were 
Table 3 Percentage of British adults aged 16 to 64 years in $1984^{10}$ and participants in the Oxford Vegetarian Study aged 16-64 years at recruitment, by BMI category

\begin{tabular}{lllll}
\hline BMI $\left(\mathrm{kg} / \mathrm{m}^{2}\right)$ & British men & $\begin{array}{l}\text { Oxford Vegetarian } \\
\text { Study men }\end{array}$ & British women & $\begin{array}{l}\text { Oxford Vegetarian } \\
\text { Study women }\end{array}$ \\
\hline 20 or under & 10 & 13.7 & 14 & 26.7 \\
Over 20-25 & 51 & 70.1 & 54 & 63.9 \\
Over 25-30 & 33 & 15.0 & 24 & 8.0 \\
Over 30 & 6 & 1.2 & 8 & 1.5 \\
\hline
\end{tabular}

\section{Key points}

- In an unusually slim cohort, the slimmest group $(B M \mid<18$ $\mathrm{kg} / \mathrm{m}^{2}$ ) had several lifestyle and dietary attributes that indicate a low risk of cardiovascular diseases. Nevertheless, we have found a significantly higher mortality in this group.

- There is no consistent pattern in the literature regarding the mortality experience of lean subjects and we are unable to explain this observation further.

- It is important that public health messages regarding healthy eating take into account the dangers of excessive food restriction, and are aimed at maintaining a healthy body weight rather than just "losing weight".

similar to the population we have studied, where a high percentage of people had a body mass index below $20 \mathrm{~kg} / \mathrm{m}^{2}$. The findings of a U shaped or J shaped mortality curve are not confirmed in two studies, which both suggested that any such relation was attributable to confounding by smoking and previous disease. ${ }^{915}$ On the other hand, the other two studies both found increased mortality in people with a very low BMI. ${ }^{16}$

We can only speculate on possible biological reasons for the increased mortality in people with low BMI. With such a low BMI it is probable that these people are consuming a very restricted diet, with important nutrients inadequately supplied. This is unlikely to be a consequence of material deprivation in our cohort because the cohort is predominantly middle class. Anorexia nervosa was not cited as a cause of death for any of the subjects in our cohort, although this condition may have been a contributory factor in some cases. It has been hypothesised that the $U$ shaped relation might result from the fact that BMI is composed of separate components (fat mass and fat free mass) with opposite effects on mortality (fat mass increasing mortality and fat free mass being unrelated to mortality/being inversely associated with mortality). ${ }^{16}$ Other researchers have suggested that the $U$ shaped curve is the result of weight loss in adult life, which has an adverse effect on longevity. ${ }^{17} 18$ We have no information on the body composition of our cohort (fat mass compared with fat free mass), or on weight at different stages of adult life, so cannot comment further.

Whereas obesity is an increasingly important public health issue, there is also concern about the prevalence of eating disorders and the social pressure, particularly on younger women, to achieve very low body weights. Our data underline the importance of avoiding extreme underweight as well as avoiding obesity. It is important that public health messages regarding healthy eating take into account the dangers of excessive food restriction, and are aimed at maintaining a healthy body weight rather than just "losing weight".

\section{Authors' affiliations}

M Thorogood, Health Promotion Research Unit, Department of Public Health and Policy, London School of Hygiene and Tropical Medicine, UK

P N Appleby, T J Key, Cancer Research UK Epidemiology Unit,

University of Oxford, UK

J Mann, Department of Human Nutrition, University of Otago, New Zealand

Funding: The Oxford Vegetarian Study is funded by Cancer Research UK.

Conflicts of interest: none.

\section{REFERENCES}

Allison DB, Fontaine KR, Manson JE, et al. Annual deaths attributable to obesity in the United States. JAMA 1999;282:1530-8.

2 Must A, Spadano J, Coakley EH, et al. The disease burden associated with overweight and obesity. JAMA 1999:282:1523-9.

3 Shaper AG, Wannamethee SG, Walker M. Body weight: implications for the prevention of coronary heart disease, stroke, and diabetes mellitus in a cohort study of middle aged men. BN 1997; 314:1311-17

4 Jarrett J, Shipley M, Rose G. Weight and mortality in the Whitehall Study. BM 1982;285:535-7.

5 Campbell AJ, Spears GFS, Brown JS, et al. Anthropometric measurements as predictors of mortality in a community population aged 70 years and over. Age Ageing 1990;19:131-5.

6 Burr ML, Lennings Cl, Milbank JE. The prognostic significance of weight and of vitamin C status in the elderly. Age Ageing 1982;1 1:249-55.

7 Thorogood M, Mann J, Appleby P, et al. Risk of death from cancer and ischaemic heart disease in meat and non-meat eaters. BM 1994;308: 1667-70.

8 Stata Corporation. Stata Statistical Software: Release 5.0. College Station, TX: Stata Press, 1997

9 Mann JI, Appleby PN, Key TJ, et al. Dietary determinants of ischaemic heart disease in health conscious individuals. Heart 1997;78:450-5.

10 Knight I. The heights and weights of adults in Britain. London: HMSO, 1984.

11 Appleby PN, Key TJ, Thorogood M, et al. Mortality in British vegetarians. Public Health Nutrition 2002;5:29-36

12 Ziebland S, Thorogood M, FullerA, et al. Desire for the body normal: body image and discrepancies between self reported and measured height and weight in a British population. J Epidemiol Community Health 1996:50:105-6.

13 Seidell JC, Versxhuren M, Van Leer EM, et al. Overweight, underweight and mortality. Arch Intern Med 1996;156:958-63.

14 Calle EE, Thun M, Petrelli JM, et al. Body mass index and mortality in a prospective cohort of US adults. N Engl J Med 1999;341:1097-105.

15 Durazo-Arvizu R, Cooper RS, Luke A, et al. Relative weight and mortality in U.S. blacks and whites: findings from a representative national population samples. Ann Epidemiol 1997;7:383-95.

16 Allison DB, Faith MS, Heo M, et al. Hypothesis concerning the U-shaped relation between body mass index and mortality. Am J Epidemiol 1997; 146:339-49

17 Lissner L, Odell PM, D'Agostino RB, et al. Variability of body weight and health outcomes in the Framingham population. N Engl J Med 1991;324: 1839-44.

18 Rhoads GG, Kagan A. The relation of coronary disease, stroke, and mortality to weight in youth and middle age. Lancet 1983;i:492-5. 